\title{
From Fiat to Crypto: The Present and Future of Money
}

\author{
Marcus M. Dapp
}

\begin{abstract}
This chapter aims to offer readers an entry point to the deep discussion of this volume and the rationale for the "Finance 4.0" system described in later chapters. What is money, why is it designed this way, and what could it become in the crypto age? The chapter contains three parts. The first part describes in rough strokes the basic functions of money and how today's fiat money system implements them. The second part offers a modest critique of the fiat money system, arguing that many problems take root in the intimate power relationship between "money and state." The final part presents two cases that address some of the shortcomings. The first is Bitcoin that infamously pursues a state-independent, decentralized conception of money. The second is Finance 4.0, a system that proposes a participatory multidimensional money system with built-in incentives for sustainable behavior. If more readers feel empowered to enter the public debate for a better money system in the twenty-first century, this short introduction achieved its aim.
\end{abstract}

\section{The Mystery of Money: What It Is and How It Works}

\author{
The study of money, above all other fields in economics, \\ is one in which complexity is used to disguise truth or to evade truth, not to reveal it. \\ — John Kenneth Galbraith
}

The author thanks Axel Apfelbacher, Mark C. Ballandies, Jürg Conzett, Carina Ines Hausladen, Dirk Helbing, and Fabian Steiner-Ligibel for helpful comments.

M. M. Dapp ( $\varangle)$

ETH Zurich, Computational Social Science, Stampfenbachstrasse 48, 8092 Zurich, Switzerland e-mail: mdapp@ethz.ch

M. M. Dapp et al. (eds.), Finance 4.0_Towards a Socio-Ecological Finance System, SpringerBriefs in Applied Sciences and Technology, https://doi.org/10.1007/978-3-030-71400-0_1 


\section{The Nature of Money}

The historian Yuval Noah Harari argues that humans acquired the ability to cooperate at large scale (beyond Dunbar's number of $~ 150$ individuals) by inventing common myths. Myths are stories that exist only in our collective imagination [1]. Along with nation, church, country, city, company, etc., money became one of the most influential collective imaginations in history. Its role is special because it allows transferring value across space and time. So far, money is the "most universal and most efficient system of mutual trust ever devised" [1]. All concepts making up the monetary system are such imaginations: from the value of coins and paper bills to the numbers on our bank accounts. A fascinating thought we could change the world by changing our imaginations...

As we use money every day without much thought, it is important to understand how it does work before discussing its future. Money is "the set of assets in an economy that people regularly use to buy goods and services from other people" [2]. In particular, money serves certain desired economic functions, which require certain physical properties of assets. Over time, different approaches have evolved into different legal types of money (Fig. 1).

To be usable as money, assets need to fulfill three economic functions [2, 3]. First, they need to be able to act as a medium of exchange. A medium of exchange is something that sellers accept from buyers in exchange for a good or service in the act of purchase. In order for the transaction to take place, it is crucial that the seller accepts the medium of exchange the buyer is offering for payment. Otherwise, the purchase will not take place.

Given mutual agreement, partners can split a transaction over time. Either the buyer receives the good before paying or the seller receives payment before delivering the good. For that to work, the medium of exchange needs to keep its value over that period. So, second, an asset used as money needs to be able to act as a store of value. The longer the time period can last, the better.

To express the value of goods in terms of other goods would be cumbersome. To say, for example: "a lunch costs the same as ten bars of chocolate, and one bar of

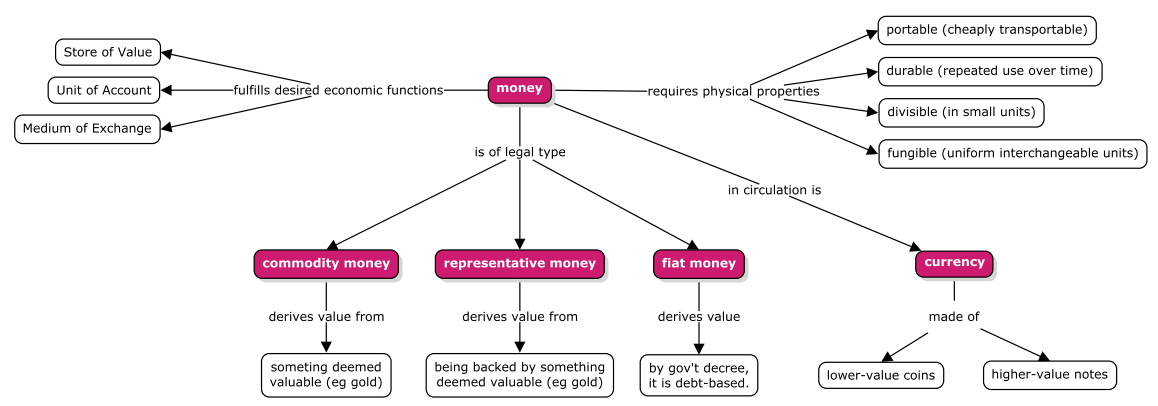

Fig. 1 Economic functions, physical properties, and legal types of money 
chocolate costs the same as two packs of chewing gum." Acceptance and use of the 'money' asset must be so widespread that people also express prices in it. In other words, the asset's third function is to act as a measure, as a unit of account.

People have used assets with different physical properties over time. The physical properties determine how well an asset fulfills the economic functions and whether it ends up serving as money. Various assets served as medium of exchange in different regions at different times: cattle, shells, nails, tobacco, cotton, copper, silver, gold, and so on. Yet, not all were money. According to Hülsmann, people used the term 'money' only when a medium of exchange was "generally accepted in society" [4].

Making an asset good money requires four physical properties [5]. (1) Fungibility means the asset is of homogeneous texture and can be portioned in equally looking pieces. Thus, it does not matter which piece one uses (in contrast, e.g., shells and cattle come in different shapes, forms, and sizes). (2) Portability means the asset can be cheaply transported from one location to another because it is neither too big nor too heavy to carry. (3) Durability means the asset does not wear off with repeated use and changing hands over time. It also should not deteriorate on its own (e.g., tobacco will rot and silver may tarnish). (4) Divisibility means the asset is usable in small fractions of the same kind to represent typical values in daily transactions (e.g., silver-made coins or paper bills).

These properties subtly guided humans when deciding what goods to use as medium of exchange, store of value, and unit of account. Over millennia, people have used and accepted precious metals for payments. In particular, gold stood the literal test of time, for good reasons. ${ }^{1}$ The advanced national economies of the last 200 years experienced an evolution of money along three different legal types (cf. Figure 1). The oldest type is commodity money that carries intrinsic value it derives from something deemed valuable in itself [2]. The Krugerrand, the most popular gold coin worldwide, is an example of commodity money. The gold it contains has value by itself as it is in demand for jewelry and other industrial purposes. In contrast, a modern banknote has no other use and thus no intrinsic value.

An important problem with commodity money is the danger of debasement. By replacing some fraction of a coin's precious metal content (e.g., gold or silver) with a cheaper base metal (e.g., copper or nickel), the issuer can profit from the difference between face value and metal value. Such diluted money loses value over time.

At this point, it is useful to introduce the term inflation. Commonly (and narrowly) defined, it is an increase in the overall level of prices [2]. To tell causes and effects apart, it is clearer to stick to the primary definition presented by Hazlitt [7]: Inflation is the increase in supply of money and credit. Each individual note and coin becomes less valuable because there are more of them available. Goods then rise in price not because goods are scarcer than before, but because notes and coins are more abundant.

Ammous [8] argues that historic periods with political regimes that avoided inflating the value of money (that was backed by precious metals) coincide with

\footnotetext{
${ }^{1}$ The Periodic Table of the Elements offers, by stepwise exclusion, a line of reasoning for gold as prime element for money [6].
} 
prosperity for nations and citizens by increased trade, investment, and innovation. Likewise, failures to keep the monetary system 'sound' led to economic decline over time. Table 1 contrasts the periods of prosperity and decline spanning two millennia, as identified by Ammous [8].

The second type is representative money that has no intrinsic value, but is instead backed by a commodity, usually a precious metal like gold or silver [9]. Its origins date back to the city-states of Venice [10] and Florence [8] in thirteenth-century Italy. Goldsmiths had started to store people's gold and silver coins for safekeeping as they owned firm buildings and safes to store the precious metals for their own trade. People handed over their coins against a small fee and got a receipt on paper to represent their coins. To get them back, they had to hand in the receipt. People realized that paying with paper receipts was more comfortable than carrying heavy coins around; they hardly came back to get their coins. This marks the beginnings of modern-day paper money and the practice of banking [10].

By analogy with commodity money, representative money faces a danger of debasement (inflation) as well. Printing more "representative" banknotes than there exist precious metals on reserve to back them may lead to a shortage when many clients want to redeem their precious metal at the same time, like during a "bank run".

Representative money flourished at the end of the nineteenth, beginning of the twentieth century, when around 50 nations were on the gold standard [8]. Governments were in direct control of gold, while citizens only held paper notes redeemable for gold. Ammous argues that the reasons "a small war in Central Europe" in 1914 was able to explode into "the first global war in human history" [8] were monetary rather than geopolitical. Early in the conflict, governments suspended gold convertibility and started to finance what became an "out-of-control arms race" [11]. Unlike during previous wars, they could now access the wealth of the entire population rather than just the government treasuries, which in the past set a natural limit to the size of wars. Without this possibility, World War I would have been much smaller in scope and duration, Ammous argues [8].

As all currencies had lost in value because of war financing, it was politically difficult to re-enter the gold standard [11]. It would have required to admit that governments significantly devalued the currency, e.g., down to $51 \%$ of prewar levels for losing power Germany. Therefore, countries took the "easier path" of currency debasement to solve their economic problems. Germany used inflation to pay for the large reparations stemming from the Treaty of Versailles-which promptly led to the infamous hyperinflation in Germany in 1922/1923, paving the way to the Nazi regime and World War II [11]. The USA also engaged in inflationary monetary policy in the 1920s, leading to the infamous October 1929 stock market crash and the decade-long Great Depression, which only ceased when the USA entered World War II in 1940. Within five years, state-imposed war production made unemployment "disappear" into the military and increased state expenses by a factor of ten [11].

The international system based on the gold standard was no longer functional, and war and economic devastation were rampant. Ammous [8] argues that money 


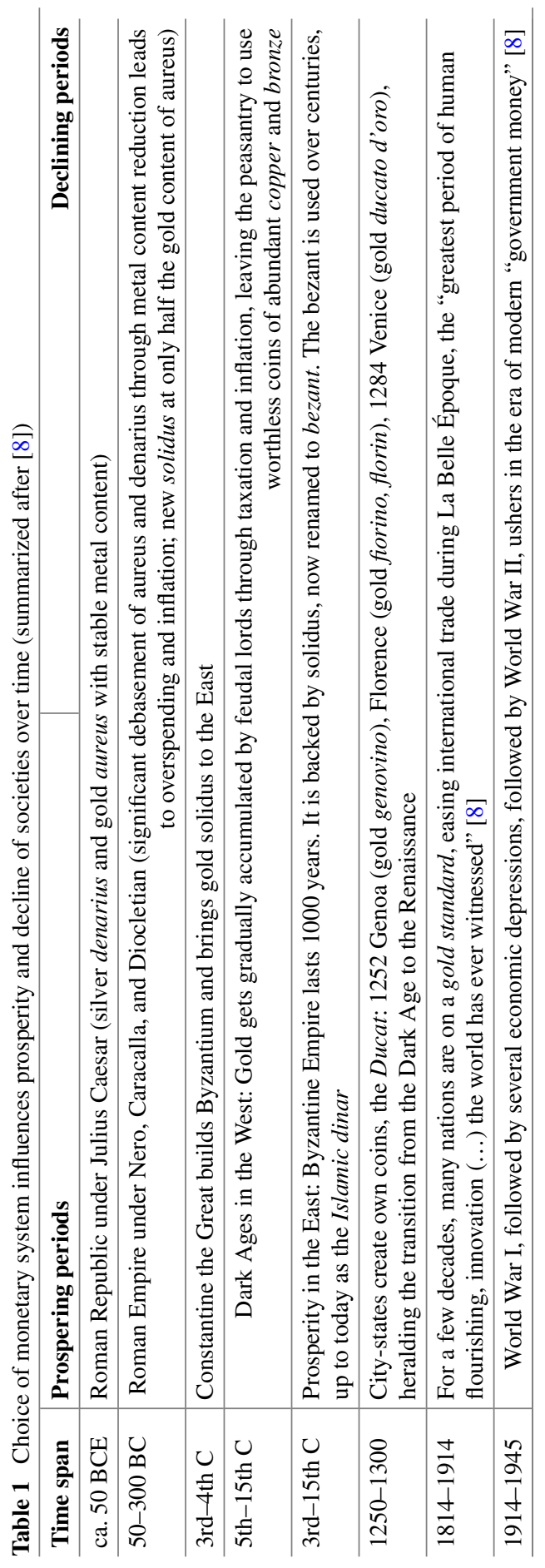


gradually turned into a politically controlled instrument rather than a market-priced commodity.

It was John Maynard Keynes who, in 1939, delivered the theoretical argument to legitimize further government intervention [12]. Keynes argued in favor of continued spending in the economy (high aggregate demand, including government spending) as it determines the overall level of economic activity. Inadequate aggregate demand, in contrast, could lead to prolonged periods of high unemployment. He argued for fiscal and monetary policies to mitigate the adverse effects during economic recessions and depressions, and restraint during prosperous times [12]. Table 2 shows the series of regulations and international agreements that unfolded to implement Keynes' ideas.

Table 2 Drift from representative money to fiat money (own research)

\begin{tabular}{c|l}
\hline 1913 & US Federal Reserve Act. Establishment of the Federal Reserve system (FED) [11] \\
\hline 1922 & $\begin{array}{l}\text { Genoa Conference establishes US dollar and British pound as reserve currencies for other } \\
\text { countries, next to gold [13] }\end{array}$ \\
\hline 1929 & US stock market crash leads to the decade-long Great Depression period [11] \\
\hline 1930 & $\begin{array}{l}\text { Bank of International Settlement (BIS) is established to facilitate reparations imposed on } \\
\text { Germany by the Treaty of Versailles after World War I. Today's role is to foster monetary } \\
\text { and financial cooperation and serve as a "bank for central banks" (cf. footnote 5) }\end{array}$
\end{tabular}

1933 Newly elected US President Roosevelt initiates "New Deal" program to counter the Great Depression [14]

Roosevelt issues Executive Order No. 6102 to "prohibit the hoarding of gold coin, gold bullion, and gold certificates within the continental United States", demanding US citizens to sell their gold at 20.67 USD per ounce to the US Treasury ${ }^{2}$

1934 US Gold Reserve Act. Among its wide-ranging provisions are: (1) confiscation of all gold owned by the FED and transfer to the US Department of Treasury, (2) prohibition to redeem dollar bills for gold, (3) establishment of the Exchange Stabilization Fund to control the dollar price without the FED, (4) authorization of the president to set a new price of gold by proclamation (sic!) [15]. The new price is 35 USD per ounce, i.e. $69 \%$ higher

1944 Agreement on the Bretton Woods System $[8,16]$ :

(1) The US dollar becomes global reserve currency with fixed exchange rates for other central banks. Currencies are convertible to USD, and (only) the USD is convertible to gold. For that, US buys gold from other countries at 35 USD per ounce. The "fixed" exchange rates can be altered to address "fundamental disequilibrium"

(2) The International Monetary Fund (IMF) is established to coordinate the global group of central banks on exchange rate stability

(3) The International Bank for Reconstruction and Development (today World Bank Group) is established to provide financial assistance for post World War II reconstruction and economic development

1971 US President Nixon announces unilateral measures to address domestic inflation and unemployment as well as the threat of an international gold run on the US ${ }^{3}$

(1) He suspends international gold convertibility for central banks, thus halting the Bretton Woods Agreement.

(2) He freezes prices and wages for 90 days and raises tariff on all dutiable imports by an extra ten percent. 
With the Bretton Woods agreement, the world had a system of fixed currency exchange rates, with the US dollar at the center as the global reserve currency, and the only one backed by gold reserves, deposited by all nations in Fort Knox. In 1971, however, US President Nixon faced a difficult situation: a high domestic unemployment and inflation rate combined with the fact that more foreign-held dollars circulated outside its borders than the US had gold reserves required action. In a swift unilateral move, Nixon announced national wage and price controls and the end of the convertibility of US dollars to gold for other countries. The announcement effectively made the Bretton Woods Agreement obsolete [11]. The "Nixon shock" decoupled the US dollar (and with it all other currencies) from the gold standard and marked the departure from representative money.

With the third type of money, fiat money, we take a final step away from grounding money in physical valuable assets as fiat money is not redeemable in gold anymore. Due to its omnipresence today, it deserves its own section.

\section{The Fiat Money System}

Fiat money is the monetary system that has gradually developed over the last few centuries and has become the globally dominant system over the last few decades. A widely used student textbook of economics defines it as "money without intrinsic value that is used as money because of government decree" [2]. In other words, printed notes and minted coins (and bank deposits) only have value because the government declared them "legal tender" to discharge debt. The government demands tax payments in legal tender, thus creating a continuous demand for its money.

The ultimate backing of the money monopoly is military state power. "Nowadays, the political power uses its power of coercion to impose a monopoly on the production and circulation of money, which in particular implies the existence of a 'legal tender', that is, a prohibition on currencies other than the 'national' currency" [17]. A national currency directs and enforces monetary policy in the domestic economy and constitutes an instrument of geopolitical power among nations. Controlling the dominant currency yields considerable benefits to the respective state like "the ability to issue securities that are always in high demand by the rest of the world" [18]. In 2020, the world is still accepting the US dollar as its reserve currency, despite tensions in trade relations and rivalry between the USA and the Republic of China.

Controlling money means primarily controlling the money supply. Figure 2 illustrates the entities and mechanisms involved in the domestic process of fiat money creation in a simplified form.

The macro-mechanism of fiat money creation is an interplay between fiscal and monetary policy, managed by an institutional setup consisting of the government

\footnotetext{
${ }^{2} \mathrm{Cf}$. https://www.presidency.ucsb.edu/documents/executive-order-6102-requiring-gold-coin-goldbullion-and-gold-certificates-be-delivered

${ }^{3} \mathrm{Cf}$. https://www.federalreservehistory.org/essays/gold-convertibility-ends
} 


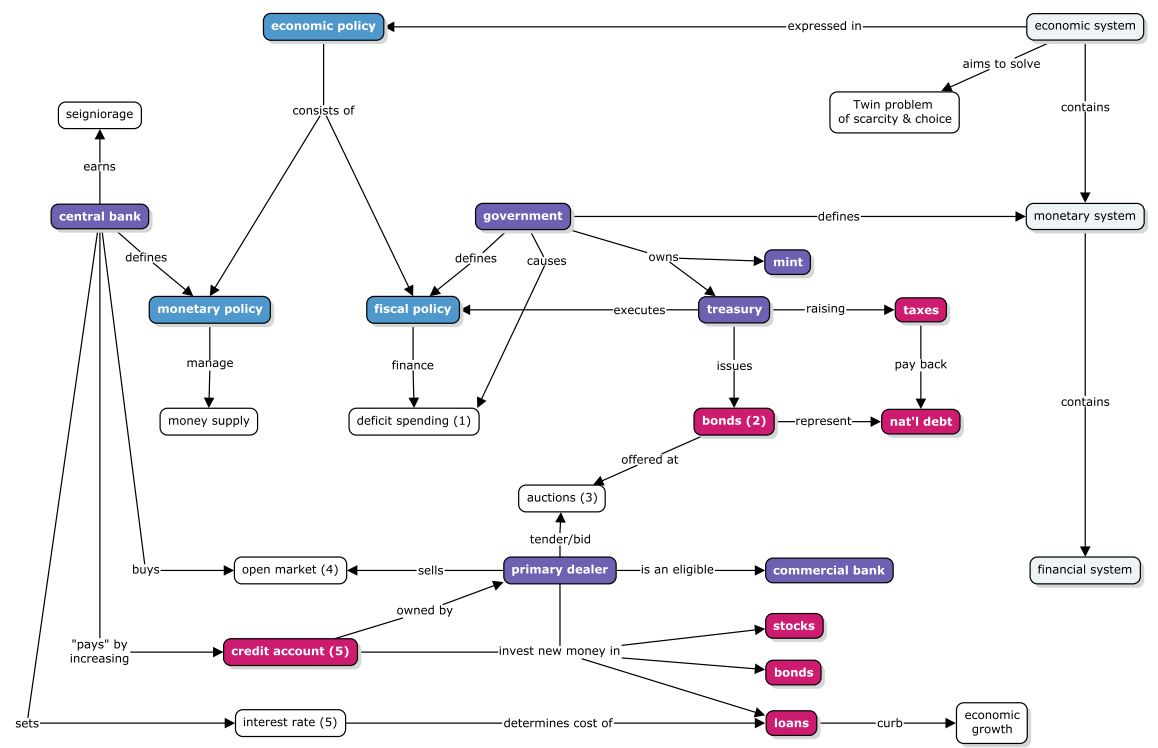

Fig. 2 Creating fiat money is an intricate interplay between fiscal and monetary policy

treasury, the central bank, and commercial banks. The mechanism comprises five steps (Fig. 2). (1) It starts with deficit spending, which means the government needs to spend more money than it currently has, maybe because of political promises made before an election. Government has two options to address deficit spending. One of the two options (leaving the third, defaulting on the debt, aside) is fiscal policy. Yet, raising taxes is usually an unpopular move for an elected government. (2) Thus remains the option to borrow money by issuing government bonds. As bonds are loans with a fixed interest rate, the government effectively commits current and future taxpayers to new, additional national debt. (3) To generate income, the government treasury holds bond auctions, in which only a selected group of commercial banks ("primary dealers") is allowed to tender, i.e., to make bids. The banks bid to buy parts of the national debt to earn interest with it. (4) In so-called open market operations, the central bank can purchase specific types of securities in the open market, directly from other market players. As counterparts in these open market operations, commercial banks sell these bonds to the central bank, at a profit. (5) To pay, the central bank simply "use[s] the computer to mark up" the credit account of the respective primary dealer on its balance sheet, thus calling new money into existence in a way "much more akin to printing money than it is to borrowing" [19].

Technically, the central bank is buying government bonds through "open market operations" (US Federal Reserve) or "asset purchase programs" (European Central Bank). In the case of the European Central Bank, one of currently five different 
asset purchase programs, the "Public Sector Purchase Program (PSPP)", deals with government-issued bonds. ${ }^{4}$

The micro-mechanism for creating money involves commercial banks and their clients. To describe it, we need to continue the story of the Venetian goldsmiths from the previous section. Realizing that most people left their precious metal coins with them for the convenience of paper receipts, some "astute goldsmiths" started to issue more receipts than they had coins in store. "[T]hey began to issue more money than they actually held in coins" [10] and increased their income without increasing reserves. This deliberate act became common practice today, known as fractional reserve banking: Banks do not need to keep 100\% of clients' deposits as reserve, but only a fraction. Since January 2012, the reserve ratio in the euro area is only $1 \%$ [20].

By converting dormant deposit money into loans, banks create new money. Fractional reserve banking permits banks to use idle deposits to generate additional interest returns on the loans issued. "[W]henever a bank makes a loan, it simultaneously creates a matching deposit in the borrower's bank account, thereby creating new money" [21]. For example, with 1 million of client money and a reserve requirement of $10 \%$, a bank can hand out ten loans each of size 1 million, thus creating 9 million in additional deposit money.

This logic rests on the assumption that clients will never withdraw all their deposits at the same time. Of course, this assumption may break during crises and lead to bank runs-a situation when a bank, in order to be able to pay out many deposits, asks many clients to repay their loans quickly. If the clients are unable to do so, the bank gets into trouble. ${ }^{5}$ Thus, the circle closes because one of the main tasks of modern central banks is to prevent such crises and ensure monetary stability among other objectives, as summarized by Ugolini [23]:

Nowadays, central bankers agree in acknowledging that they are entrusted two main (possibly conflicting) tasks: securing financial stability and monetary stability. The former task consists of the provision of the microeconomic central banking functions: the management of the payment system, lending of last resort, and banking supervision. The latter task consists of the provision of the macroeconomic central banking functions: the issuance of money and the conduct of monetary policy.

Reflecting on these mechanisms of creating fiat money leads to a number of critical remarks.

\footnotetext{
${ }^{4}$ Cf. https://www.ecb.europa.eu/mopo/implement/omt/html/index.en.html.

${ }^{5}$ The Basel Committee on Banking Supervision (BCBS) as part of the Bank for International Settlement (BIS) is composed of central banks from 28 jurisdictions. It issues the "Basel Accords", a set of recommendations on banking supervision and risk management, regulating minimum capital requirements including risk weights for asset classes. "Basel III", intended as a response to the Global Financial Crisis 2008/2009, was agreed in 2010 to put stricter risk management metrics for banks by 2015. It was extended repeatedly and will, most recently because of COVID-19, not be implemented earlier than 2023, over a decade later [22].
} 


\section{A Modest Critique of Money}

Analyzing the mechanisms of the fiat monetary system reveals several issues that warrant a closer look. The following critique cannot be exhaustive, but aims to raise some issues that are particularly relevant with regard to the proposals laid out in the last section and the main chapter on "Finance 4.0" of this volume.

\section{Fiat Money Is Debt-Based}

Fiat money is created as debt in the moment of issuing loans [24]. A new asset purchase by a central bank or a new loan by a commercial bank increases the money supply in a subtle way that is invisible for most people. "Debt-based" means that an amount someone owns represents an equal amount of debt for someone else in the system. Hence, creating new money means creating new debt. Nations with fiat money systems tend to accumulate debt over time. ${ }^{6}$ Creating money from "thin air" also permits banks (and governments) to gain excessive financial and political power in relation to all other members of society. Moreover, the fiat money system misleads the world to live beyond its means and thus expedites the sustainability crisis.

How to reduce debt? According to Dalio [25], governments have four options to reduce debt and debt service: (1) austerity policy (i.e., spending less); (2) debt defaults/restructuring; (3) the central bank creating money, making purchases or providing guarantees; (4) redistributing money and credit from "those who have more than they need to those who have less."

The first two options are unpopular among governments as they are hard to explain to voters. A policy of austerity can be devastating as falling prices may lead to a downward feedback cycle of falling asset prices and increasing unemployment ("deflationary shock"), which may end in debt defaults of many businesses. The fourth option, to transfer money/credit between stakeholder groups, is also delicate as powerful voter groups may lose out and thus fight the policy. For officials aiming for re-election, this is a problematic situation. Besides, there are often legal issues when governments interfere with private property.

This leaves governments with the third option: "creating money" to finance the debts as discussed in the previous section. Under normal circumstances, the typical inflation target hovers around 2\% (a coincidental and arbitrary number [26]), which is a money creation rate that only experts recognize. Most voters do not realize the continuous price increases although at this $2 \%$ rate prices double every 35 years. The consequence is an ever increasing amount of government debt, for which all citizens need to pay. Where do the countries stand today? The Managing Director

\footnotetext{
${ }^{6}$ In 2012, the EU created the 'European Stability Mechanism', an intergovernmental organization in Luxembourg, with the mission to provide financial assistance in the form of 'ESM loans' to member countries experiencing financing problems, like Cyprus and Greece in the past. cf. https:// www.esm.europa.eu/assistance/lending-toolkit.
} 

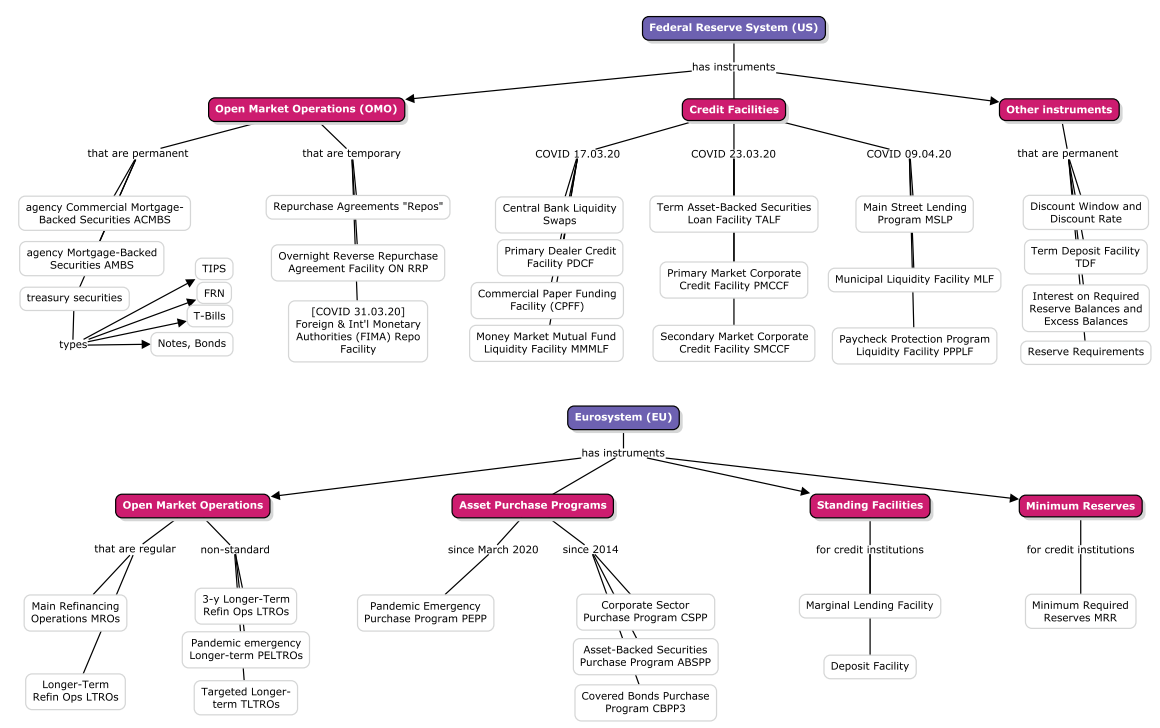

Fig. 3 Arsenal of central banking instruments of Federal Reserve System and Eurosystem

of the International Monetary Fund (IMF) stated that global public debt will reach a "record-high of about 100 percent of GDP in 2020" [27].

\section{Distortion of Price Signals}

As illustrated for the Federal Reserve System $^{7}$ and the Eurosystem ${ }^{8}$ in Fig. 3, analyzing the opaque arsenal of central bank instruments is a staggering experience. Most people would have a hard time realizing and understanding the implications of running these complicated structures.

\footnotetext{
${ }^{7}$ For the Federal Reserve System instruments, cf. https://www.federalreserve.gov/monetarypolicy/ policytools.htm.

${ }^{8}$ For the Eurosystem instruments, cf. https://www.ecb.europa.eu/mopo/implement/omt/html/index. en.html.
} 
End of October 2020, the stock of all asset purchase programs managed by the Eurosystem stood at 3,470 trillion EUR, while the balance sheet of the Federal Reserve stood at 7,157 trillion USD. In other words, each of the many instruments has the potential to inject hundreds of billions into the monetary system. ${ }^{9}$ It is important to understand that all this new money is created as credit (debt) without an equivalent increase in the production of goods and services in the real economy. Channeling so much new money into the system leads to an upward pressure on price levels in the market, because the additional money available is not matched by more goods and services. Hence, assets, goods, and services are becoming more expensive in terms of monetary units (USD, EUR, etc.) to be spent for consuming them or investing into them, solely because the monetary base is inflated without any change in the real economic conditions. From January 2009 to September 2020, the Consumer Price Index ${ }^{10}$ for urban consumers in the US (CPI) rose by $23 \%$ and the Harmonized Index of Consumer Prices in the EU (HICP) by $19 \% .^{11}$

Economies are complex socioeconomic networks with nonlinear relationships, i.e., causes and effects are not proportional to each other [28]. The effect the central bank has on employment decisions by businesses via influencing the conditions for commercial bank loans is one example for such a nonlinear relationship. However, the assumed logic — cheaper loans lead to investments and higher levels of employment—-may not work as intended. Rather, one may find "jumpy", nonlinear behavior for a variety of reasons: (i) banks may not pass the money on as loans, but channel it to other markets such as stocks; (ii) businesses may not take out loans to avoid additional debt in difficult times; or (iii) businesses may take out loans but not use them to keep staff or expand, but to buy back shares. When making such decisions, banks and businesses may take "private" information (unknown and unknowable to the central bank) into consideration and decide in unintended ways. Anything between none and all three options may happen at the same time, leading to seemingly contradictory effects. For example, some businesses may go insolvent ${ }^{12}$ for lack of orders, while excess money flows into asset markets. Thus, inflated prices may become "visible" outside consumer price indices: in rising stock prices, rising gold and silver prices, or rising real estate prices.

\footnotetext{
${ }^{9}$ For the ECB figure cf. previous footnote plus figure from https://www.ecb.europa.eu/mopo/imp lement/pepp/html/index.en.html. For the FED figure cf. https://www.federalreserve.gov/monetaryp olicy/bst_recenttrends.htm.

${ }^{10}$ Consumer price indexing, the official metric for inflation, is challenged because the composition of the reference basket of goods, dynamic adjustments, etc. significantly influence the price tracking. In contrast, crowd-sourced indices like the Chapwood Index for the US show consistent higher inflation rates: https://chapwoodindex.com/. For an introduction to the debate, see: https://www.inv estopedia.com/articles/07/consumerpriceindex.asp.

${ }^{11}$ For the US cf. https://fred.stlouisfed.org/series/CPIAUCSL, for the EU cf. https://sdw.ecb.eur opa.eu/.

${ }^{12}$ Or, they may not go insolvent but turn into so-called "zombie companies", unable to pay the interest on their loans, but kept alive by very low interest rates and/or government support. About 16-36\% of companies in the EU in 2019 [29] and about 20\% in the US in 2020 [30] are considered to be zombie companies. Directing funds away from healthy companies is a major concern as it may depress employment and growth in the future.
} 
It is very hard to predict and control how central bank money ends up being used. In other words, central banks pursue this approach without knowing when they reach a tipping point that causes the system to shift to a new regime [28]. Such a new regime could be hyperinflation, an asset bubble burst, or a wave of insolvencies and unemployment. All of them may lead to large fractions of the general public and financial markets to lose trust in the stability of the national currency, resulting in bank runs and large declines in currency value (relative to other currencies or assets). Consequently, the acceptance of money in exchange for goods or services deteriorates and the common myth of money starts to collapse [1]. Evaluating empirical data on such tipping points is sobering. Since 1800, bank runs (affecting one bank), bank panics (affecting several banks), or banking crises (affecting entire countries) are happening every 7-10 years on average, with no significant difference between advanced economies and emerging markets [31].

Finally, as this additional money needs to enter the economy at some point and then start moving from one market participant to the next, the so-called "Cantillon effect" plays out [32]. The first users of new money can still use it to buy goods at unchanged prices. However, with each market transaction, the information about the new money spreads in the markets and prices gradually adjust. In other words, there is a re-allocation of resources "in favor of those economic agents that receive the new money first" [32]. The question then is: who in society benefits from new money first?

Overall, increasing the money supply in the absence of an increase in economic activity causes distortions in the price levels and puts a large group of market participants in difficult positions.

\section{The Economy Is Complex, Not Just Complicated}

From a systems science perspective, the main question is: How do we think a small group of people with a narrow set of goals and a one-dimensional metric can steer a complex economic network consisting of millions of individuals, to a state of comprehensive well-being for the majority?

Ad "small group": The Governing Council of the Eurosystem consists of 22, the Federal Open Market Committee of the FED of 12 individuals [33]. These two groups are steering the economic lives of 330.5 million inhabitants in 52 US states and 447.7 million inhabitants in 27 EU countries. ${ }^{13}$ No matter how much staff assigned or which key metrics used, it seems to be impossible for 34 humans to get a sufficiently deep understanding of these enormous (and enormously diverse) economies in order to decide top-down what the single best monetary policy is for everyone.

Ad "narrow goals": Contemporary economics puts an undue focus on one goal monetary efficiency - at the neglect of health, sustainability, happiness, well-being,

\footnotetext{
${ }^{13}$ Cf. https://www.census.gov/ and https://www.statista.com/statistics/253372/total-population-ofthe-european-union-eu/.
} 
and other societal goals many deem important [24]. The FED's monetary policy is "to promote maximum employment, stable prices, and moderate long-term interest rates in the US. economy" [34]. The primary objective of the ECB's monetary policy is to maintain price stability. The ECB aims at inflation rates of "below, but close to, $2 \%$ over the medium term" [35]. In other words, the primary goal of central banks is to mitigate price rise, i.e., inflation, which is the key design feature of a fiat money system in the first place. This narrow goal, only to make the fiat money system work, stands against the "Agenda 2030", a holistic set of 17 goals aiming at global sustainable development, unanimously adopted by 193 member states of the United Nations in 2015 [36]. Yet, the monetary system, which dominates world affairs, lacks transparency, democratic governance and legitimacy. How is this possible?

Ad "one control metric": Using a one-dimensional metric for decision-making and resource allocation is dangerous and can considerably affect the functioning of the overall system of society. Other complex systems use diverse variables, i.e., a multi-dimensional approach, to steer the entire system [37, 38]. The human body, for example, uses several mechanisms (nervous system, hormone system, immune system, etc.) to keep the overall organism well-performing, where even the brain does not control all processes (cf. the chapter on "Qualified Money" in this volume). In the same vein, steering modern complex economies may require more complex, multi-dimensional feedback mechanisms for a self-organization of society towards overall prosperity and well-being [39].

Accordingly, Dosi and Roventini [40] make the case for "agent-based models as the standard way of theorizing in macroeconomics". They see the economy as a complex evolving system, an ecology populated by heterogeneous agents, whose far-from-equilibrium interactions continuously change the structure of the system.

In closing, I would briefly like to mention that the failure of the majority of economists to adequately predict the financial crisis 2008/2009 has caused a largescale critical discourse within the economics discipline [41, 42]. Felber presents a collection of wide-ranging criticisms that go as far as accusing the economic profession of mathematical fetish and "physics envy", of theory monoculture and narrowness in teaching [43]. As a consequence, an international student initiative for "Pluralism in Economics"14 has formed in 2014, consisting of 82 associations of economics students from 31 countries. It calls for an "overhaul of the way their subject is taught" [44]. The dominance of narrow free-market theories at top universities, it claims, harms the world's ability to confront challenges like financial stability and climate change.

\section{Separation of State and Money in the Digital Age}

Central banks have limited control over how newly issued money is used (cf. the discussion on 'price signals' above). This is the main argument they put forward

\footnotetext{
${ }^{14} \mathrm{Cf}$. http://www.isipe.net/.
} 
in favor of "central bank issued digital currencies (CBDC)". Several institutions published reports on CBDC in 2020 [45-49]. Note, however, that digital currencies in this context and cryptocurrencies as discussed further below are entirely different concepts.

According to the International Monetary Fund (IMF), CBDC would give central banks a "fast and direct means to provide fiscal assistance to vulnerable populations during the emergency, including to the unbanked" [49]. CBDC allows injecting new money directly into (newly created) central bank accounts for businesses and citizens. The money could bypass the banking system, which is believed to reduce the liquidity squeeze short-term and the dangers of inflation long-term.

Central banks see several advantages of digital currencies: (1) faster and cheaper payment processing as large parts of the banking industry could be circumvented; (2) more effective policy measures because of better targeting of groups and individuals; (3) easier introduction of unpopular measures such as negative interest rates, from which citizens could not escape as cash withdrawals would cease to exist, thus rendering bank runs impossible.

It is important, however, to understand the severe implications of CBDC for citizens. (1) It will be possible to track all transactions of all citizens and businesses in real time. Making anonymous cash payments will be impossible, even for completely legal transactions, thereby threaten privacy rights. (2) Governments can use transaction data to personalize fiscal policies (e.g., automatic taxation) and fiscal benefits (e.g., automatic basic income). Subjugating these activities under democratic accountability processes will be hard. The door for behavioral economists to nudge, manipulate, or even prevent transactions for certain people will be wide open.

A new Surveillance Monetarism may arise, akin to Surveillance Capitalism [50], only with different actors. Governments or central banks may analyze citizens and influence their behavior with programmable CBDC and Artificial Intelligence. They will become even more capable to track citizens and to conceal operations within the already opaque fiat money system.

This new capability may have geopolitical implications when the CBDC is issued by a large economic power (e.g., China, USA, EU). They may pressure trading partners to accept their CBDC as they do with fiat currency today. ${ }^{15}$ In addition, the foreign CBDC will put the partner countries' citizens at risk of being monitored by a foreign power. Thus, large and powerful 'suppliers' of a CBDC may be at an advantage in bargaining monetary hegemony.

In his treatise against cash, Rogoff [51] presents a devious plan for ways that governments can use to lure the population into letting go of cash. His recommendations for phasing out paper currency are [51]: (1) make it more difficult to engage in anonymous untraceable transactions repeatedly and on a large scale; (2) stretch the transition phase over 10-15 years to avoid excessive disruptions and give institutions and people time to adapt; (3) give incentives to opt-in like free smartphones and free accounts.

\footnotetext{
${ }^{15}$ The effect, called "Dollarization" or "Euroization", is an example of currency substitution that can happen with CBDC for similar reasons, but much more efficient.
} 
However, Rogoff's conception of essential aspects of cryptocurrencies in general and Bitcoin in particular has flaws [51], which is a reason for hope that there will be a more positive 'future of money.' When it becomes clearer to more people, how the current monetary system perpetuates disadvantages for a majority of citizens and businesses, while new systems would offer advantages for many or all, history may take another turn this time. In fact, the promise of 'crypto money' is to democratize the creation and management of money in society.

\title{
The Many Futures of Money
}

\begin{abstract}
I don't believe we shall ever have a good money again before we take the thing out of the hands of government, that is, we can't take it violently out of the hands of government, all we can do is by some sly roundabout way introduce something that they can't stop.
\end{abstract}

-F.A. Hayek (1984)

The goal of my final section is to introduce new ways of thinking and designing monetary systems in order to stretch the imagination for what might be possible. I personally expect a greater diversity of digital incentive systems ('crypto monies') in the future.

To illustrate the spectrum, let me introduce and discuss only two examples here. Both share a few commonalities: (i) They differ significantly from the dominant fiat money system, albeit in different ways; (ii) both would not be possible without distributed ledgers, blockchain technology, and smart contracts; (iii) both share the unconventional idea that money can and should be democratic.

The two examples also differ in significant ways from each other: (i) One aims for 'world dominance' while the other is explicitly complementary in nature; (ii) one implies a winner-takes-all dynamic, while the other foresees a plurality of monies for different purposes; (iii) one is criticized for its energy consumption, while the other has sustainability at its core; (iv) one is in productive use already for a decade, while the other is still at the level of a research and demonstration project.

\section{Bitcoin, a Radical Idea Refusing to Die}

The root problem with conventional currency is all the trust that's required to make it work. The central banks must be trusted not to debase the currency, but the history of fiat currencies is full of breaches of that trust.

-Satoshi Nakamoto (anonymous inventor of Bitcoin)

The main question regarding Bitcoin, the oldest cryptocurrency project (and largest in monetary terms), is not, where the Bitcoin price will go. It is rather, why is Bitcoin still alive in 2020 and why do people think it is even valuable? 
Twelve years ago, the Bitcoin project started with a white paper and a tiny piece of software code serving as a proof of concept [52]. It took a while until the cryptography community fully appreciated its design and started to contribute open-source code and to develop the underlying technical system. Against all odds, what started as a software network experiment of a few cryptography nerds, ended up becoming a global phenomenon valued at 320 billion USD as of this writing (November 2020). A few numbers for comparison: (1) This is more than the Gross Domestic Product of $80 \%$ of the 195 countries monitored by the IMF [53]; (2) to replace the "inefficient global foreign exchange market" [8], Bitcoin would need to be valued in the vicinity of 5 trillion USD or a factor of 15 higher; (3) to reach gold's market value, Bitcoin's valuation would need to reach 8.4 trillion USD or 26 times its current value [54]. These factors seem enormous and unattainable. Yet, over the last decade, the valuation grew from 0.01 USD to 10'000 USD per bitcoin. That is a factor of 1'000'000. ${ }^{16}$ Why do people think Bitcoin deserves this valuation?

Note how the monetary properties of the Bitcoin system contradict those of the fiat money system. First, consider its "absolute scarcity" in supply [8]. Roughly every ten minutes, a new block of transactions is created and the miner receives a reward called "block subsidy". Starting with 50 bitcoin initially, this block subsidy is halved every 210 '000 blocks. As the number of halvings is limited to 64 (of which only 3 have passed so far), the overall sum will approach but never exceed 21'000'000 bitcoin. This hard cap is the exact opposite of the ever-increasing money supply in the fiat money system.

Second, consider its "unforgeable costliness" of creation [55]. Similar to gold mining, the process of creating new bitcoin needs a proof requiring a significant and usually increasing amount of computing work to be done. And there are no shortcuts: The "proof of work" algorithm is a contest to guess a large number with certain characteristics (called a "hash") for which no faster mathematical method than trialand-error is known. At the time of writing, the Bitcoin network needs to calculate and test approx. $10^{18}$ hashes per second to construct a new valid block within ten minutes. Dissimilar to gold, the difficulty level increases with increasing computing capacity, while the rewards decrease over time (due to the halving mentioned above). Using a stock-to-flow model, the prediction is that from 2024 onward, Bitcoin will be harder to "mine" and thus grow less in supply than gold that has been used as a store of value for millennia [56].

So, what are Bitcoin's key properties that allowed it to become such a radically different monetary system? People typically ascribe a set of properties to Bitcoin similar to the ones listed in Table 3.

To fully understand Bitcoin, it is crucial to acknowledge the fact that only some properties are design properties, consciously determined by the Bitcoin developers at the outset of the project. Some others (marked with * in Table 3) are emergent properties of the complex system that Bitcoin represents. The latter have not been

\footnotetext{
${ }^{16}$ It is an interesting design fact that Bitcoin has not two digits like most fiat currencies, but eight. That means that $100,000,000$ Satoshis (the smallest unit) make 1 BTC. In other words, Bitcoin is many orders of magnitude more divisible than any money humans ever used.
} 
Table 3 List of properties typically ascribed to the Bitcoin system

\begin{tabular}{l|l}
\hline $\begin{array}{l}\text { Open: The Bitcoin software is free and open } \\
\text { source }\end{array}$ & $\begin{array}{l}\text { Borderless: Being a global network, } \\
\text { national borders can not restrict transactions }\end{array}$ \\
\hline $\begin{array}{l}\text { Decentralized*: Bitcoin's governance is not } \\
\text { hierarchical }\end{array}$ & $\begin{array}{l}\text { Distributed: The underlying network is } \\
\text { peer-to-peer rather than a client/server } \\
\text { architecture }\end{array}$ \\
\hline $\begin{array}{l}\text { Permissionless: There are no barriers to using } \\
\text { Bitcoin }\end{array}$ & $\begin{array}{l}\text { Censorship resistant: Neither transactions } \\
\text { nor users can be blocked }\end{array}$ \\
\hline $\begin{array}{l}\text { Immutable*: The Bitcoin ledger storing all } \\
\text { transactions cannot be modified unilaterally in } \\
\text { retrospect }\end{array}$ & $\begin{array}{l}\text { Trustless*: Performing transactions on the } \\
\text { network requires no trusted third parties }\end{array}$ \\
\hline
\end{tabular}

consciously planned for (nor could they). However, they have been spontaneously emerging over time because of the monetary properties described above. This allowed a specific incentive system between users and miners in the network to self-organize.

Immutable: Bitcoin's monetary policy dictates how new bitcoin come into existence. Some critics argue that software developers could simply change the software code, and then, Bitcoin would behave differently, have no hard cap, different block subsidies, etc. Yet, getting a different software code accepted into the official code repository is not straightforward at all. Bitcoin's code is open-source software. That means if developers disagree with the direction the project is taking, they can always take a copy of the code base and create an alternative path. Such departures, called forks, usually mean a split (and, thus, a weakening) of the currency - and of the community. Despite several forks (Bitcoin Cash, Bitcoin Satoshi's Vision, Bitcoin Gold, and others), Bitcoin is still, by far, the most valued cryptocurrency network.

What would it take to rally the majority of the network nodes behind a software change to switch to a different monetary policy? In the case of increasing the number of bitcoin or introducing inflation, it would require to convince a majority of Bitcoin nodes to alter the network against their financial interests. This is unlikely, because neither users nor miners have an incentive to change the Bitcoin code to create more bitcoin retrospectively and thus inflate the existing supply (collectively owned by them).

Trustless: Through the combination of mining rewards and transaction fees, miners have a monetary incentive to process transaction blocks, thus keeping the network secure, alive and functioning as users expect it: this allows them to transact digitally world-wide without the need for any intermediaries. Cheating (e.g., by double spending bitcoin) became more difficult over time as it requires to control more than half of the immense computing power needed to mine transaction blocks.

Decentralized: Over time and all over the world, the Bitcoin system attracted an increasing number of participants, users, and miners to the network. The Bitcoin network currently consists of roughly 10'000 listening nodes worldwide. 
$25 \%$ of them do not reveal their country location. ${ }^{17}$ Mining needs initial investments, but anyone can start to run their own full node and support the Bitcoin network.

Altogether, Bitcoin's emergent properties make it a radically different monetary system from what humans have known so far. They are also the cause for why it is becoming harder to change Bitcoin's inner workings, the longer it lives.

Now, assuming its design will remain stable, what could Bitcoin become like in the future? If the trajectory of absolute scarcity of supply, unforgeable costliness of creation, and immutable monetary policy will remain stable, Bitcoin may challenge the global economic order in a couple of years [57]. If it continues to survive, Bitcoin may become the first instance of "sound money" as theorized by Austrian Economics $[8,58]$ or "ideal money" as proposed by Nash [59].

At some point, some governments may consider using Bitcoin due to high national debt or geopolitical challenges, e.g., surveillance monetarism imposed by a foreign CBDC. They may find a hard, stable asset, which is less prone to international geopolitics, to be more attractive than to continue defending their national currency. Bitcoin could also become attractive for central banks to hold as a complementary reserve asset to gold.

In 2020, the corporate sector has been starting to move into Bitcoin. The first few publicly traded companies announced to store large sums of treasury funds in bitcoin in order to reduce risk exposure to fiat currencies. ${ }^{18}$

So, what is it that Bitcoin is accomplishing? In the words of Bratton: "If nothing else, Bitcoin has made money into a general design problem, as it should be, and not just the design of financial products or the look of paper bills, but of vessel abstractions of time, debt, work, and prestige" [60].

To illustrate the wide spectrum of cryptocurrency designs, let me now introduce another design proposal, which is the result of rethinking how new kinds of money could be used to promote inclusive socio-ecological development - the main topic of this volume.

\section{Finance 4.0, a Socio-Ecological Financial System}

We started from the working hypothesis that at the core of most societal problems are non-sustainable practices and misaligned incentive schemes. Currently, a boundless, globalized economy is systematically creating negative externalities. This is not being sanctioned sufficiently, because globalized regulation is not effective enough. The monetary system adds to that by not setting the required incentives from within as it feeds on two human traits: the cognitive bias to prefer a reward that arrives sooner over one that arrives later ("hyperbolic discounting" or "low time preference") and

\footnotetext{
${ }^{17} \mathrm{Cf}$. statistics and map of listening nodes on: https://bitnodes.io/. The number of full nodes is not directly measurable, but estimated to be up to ten times larger.

${ }^{18} \mathrm{Cf}$. https://bitcointreasuries.org/ for a curated list.
} 
the inability of properly comprehending the long-term outcomes of an action while deciding ("temporal myopia") [61].

Today's monetary system leads to a preference of short-term thinking and acting, thereby overlooking or ignoring the long-term consequences. Therefore, we need to re-arrange our societal incentive systems toward long-termism: "[f]rom a global perspective, what matters most (in expectation) is that we do what is best (in expectation) for the general trajectory along which our descendants develop over the coming millions, billions, and trillions of years" [62].

What is needed is monetary innovation, experimentation, and competition to create a new relationship between money and sustainable practice. The good news is: We already have parallel, state-independent complementary currency systems: ${ }^{19}$ Since the 1980s, approx. 3'500 to 4'500 such systems have been recorded in more than 50 countries [10,63].

If complementary currencies, i.e., alternatives to the current system, provide evidence of successfully addressing some societal challenges, why are they not more researched, discussed, and written about in mainstream economics? Hülsmann argues that economists, too, act within an incentive system. While "championing government involvement in money and banking pays the bills, promoting the opposite agenda shuts the doors to an academic career. No consistent economist could expect monetary economists to lead campaigns against central banks and paper money" $[4,24]$.

Nevertheless, I would like to argue that money should aim at mitigating the problem of negative externalities and at providing incentives toward sustainable practice.

The current monetary system only optimizes for one goal—profit maximization. Instead of optimizing only for "more money", while neglecting other vital goals, the monetary system should enable many feedback loops, to reflect the multitude of goals humans have. Letting people create their own "monies" around these goals will foster self-organization of markets for different externalities and enable the coevolution of different, distinct incentive systems (cf. the chapters on Qualified Money and Finance 4.0 in this volume).

Using tokens to represent incentives is a concept from psychology that suggests that incentive systems with tokens work best when the tokens are abstract, provide immediate feedback, and lead to a bigger, longer-term reinforcer [64]. However, to avoid nudging [65] and the dangers of top-down manipulation [66], it is important that users are self-sovereign in creating and deciding on the actions they want to incentivize and the tokens they want to use.

Many environmental and social problems are an example of a "commons dilemma, a social situation in which a collective cost or risk is generated via the combined negative externalities of numerous individuals who act rather independently from

\footnotetext{
${ }^{19}$ They are defined as a "unit (or system) of account that complements the official currency and has been developed by a group of agents (individuals, economic and social structures, local authorities or banks) that has formed a local network with a view to accounting for and regulating exchanges of goods and services" [63].
} 
one another" [67]. Elinor Ostrom laid seminal groundwork by presenting principles to overcome the commons dilemma by a common-pool resource management that is effective for small, interconnected communities [68]. Scaling these to large, anonymous networks, however, is a challenge, that required polycentric approaches in the past.

The emergence of distributed ledger technology and the token engineering/cryptoeconomics discipline now allows us to implement and collectively coordinate such sociotechnical complex systems at scale. The decentralization and immutability of "blockchains" and "smart contracts" enable us to co-design and co-monitor the rules needed to make the network produce positive action [69].

Put differently, cryptoeconomics has the potential to create a scalable peer-topeer governance model for managing the commons. Smart incentive design could be a way to encourage more long-term thinking and succeed by establishing mechanisms that reward long-term, sustainable behaviors on the scale of the Internet.

Rethinking the notions of value and money and shifting toward long-term thinking are necessary to create the social ecosystems - Harari's "collective imaginations" [1] - that can collaboratively change our world from an extractive to a regenerative one. Table 4 contrasts the two paradigms in terms of system goals, structure, and rules.

The core idea of the Finance 4.0 system, which will be detailed in the corresponding chapter in this volume, is to propose design principles and a technological infrastructure for a socio-ecological finance system that aims to maintain the commons and reduces negative externalities. Hence, the core design principles of the Finance 4.0 system are:

- The system encourages a multi-dimensional incentive design to address different externalities and strengthen the commons by focusing on socio-ecological goals.

- The system allows for and encourages the bottom-up creation of tokens to distribute the power to design and create money.

Table 4 Contrasting the paradigm of the current financial system with the Finance 4.0 system

\begin{tabular}{|c|c|}
\hline Current financial system & Finance 4.0 system \\
\hline $\begin{array}{l}\text { System goals are one-dimensional (profit } \\
\text { maximization) and self-referential (targets, e.g., } \\
\text { money supply, interest rate, employment), } \\
\text { thereby ignoring important societal goals such } \\
\text { as protection of nature, health, or social } \\
\text { cohesion }\end{array}$ & $\begin{array}{l}\text { System goals are pluralistic and } \\
\text { socio-ecological in nature, using tokens as a } \\
\text { multi-dimensional information signal and } \\
\text { money substitute to promote positive action to } \\
\text { benefit society at large }[39,70,71]\end{array}$ \\
\hline $\begin{array}{l}\text { System structure, consisting of governments, } \\
\text { central banks, international financial } \\
\text { organizations is hierarchical and only partly } \\
\text { democratically legitimized }\end{array}$ & $\begin{array}{l}\text { System structure is peer-to-peer, consisting of } \\
\text { markets for positive action and dynamic } \\
\text { governing bodies that are participatory and } \\
\text { decentralized }\end{array}$ \\
\hline $\begin{array}{l}\text { System rules are defined top-down by the } \\
\text { institutional structure through fiscal and } \\
\text { monetary policy on national and international } \\
\text { level }\end{array}$ & $\begin{array}{l}\text { System rules for positive actions, token } \\
\text { markets and governing bodies are } \\
\text { self-organized and democratically governed } \\
\text { with all users being able to participate }\end{array}$ \\
\hline
\end{tabular}


- The system encourages the bottom-up creation of token designs and their use via a permissionless, distributed peer-to-peer network.

- The governance of the system is democratic and decentralized to ensure division of power and continuous design for value.

Finance 4.0 is a new kind of monetary system, which makes systemic interventions more effective [72]. By considering different goals, Finance 4.0 can adapt its function over time and as required. By enabling self-organization at all levels, users hold the power to change the system, and let it evolve according to needs. Through the underlying rules of the cryptoeconomic system, incentives, punishments, and constraints can be co-designed [73]. They will co-evolve under the control of the users.

In summary, the new paradigm of the Finance 4.0 system opens new pathways that the current monetary system does not offer. It allows for monetary innovation by 'invitro' experiments exploring the post-fiat-monetary design space. I hope communities around the world will benefit from this chapter by finding and choosing, creating, and nurturing a prosperous economic system that respects their socio-ecological goals.

\section{References}

1. Y.N. Harari, Sapiens: A Brief History of Humankind (Signal Books, 2014)

2. N.G. Mankiw, Principles of Economics, 7th edn. (Cengage Learning, Stamford, CT, 2015)

3. Aristotle, Nicomachean Ethics, Book 5, Chapter 5, http://www.perseus.tufts.edu/hopper/text? doc $=$ Perseus:text: $1999.01 .0054:$ book $=5$ : chapter $=5$ \&highlight $=$ shoemaker

4. J.G. Hülsmann, The Ethics of Money Production (Ludwig von Mises Inst, Auburn, Ala, 2008)

5. Aristotle, Politics, Book 1, Section 1257a, http://www.perseus.tufts.edu/hopper/text?doc=urn: cts:greekLit:tlg0086.tlg035.perseus-eng1:1.1257a

6. NPR, Why Gold? A Chemist Explains Why Gold Beat Out Other Elements, in Planet Money, Morning Edition (NPR, 2011)

7. H. Hazlitt, What You Should Know About Inflation, 2nd edn. (D. van Nostrand, New York, 1965)

8. S. Ammous, The Bitcoin Standard: The Decentralized Alternative to Central Banking (Wiley, Hoboken, New Jersey, 2018)

9. D. Lee (ed.), Handbook of Digital Currency: Bitcoin, Innovation, Financial Instruments, and Big Data (Elsevier/ AP, Amsterdam, 2015)

10. B.A. Lietaer, J. Dunne, Rethinking Money: How New Currencies Turn Scarcity into Prosperity (Berrett-Koehler Publishers, San Francisco, 2013)

11. R.E. Parker, R. Whaples (eds.), Routledge Handbook of Major Events in Economic History (Routledge, London; New York, 2013)

12. J.M. Keynes, The General Theory of Employment, Interest and Money, Vol. VII (Cambridge University Press for the Royal Economic Society, Cambridge [England] ; New York, 2013)

13. E.W. Kemmerer, Gold and the Gold Standard: The Story of Gold Money, Past, Present and Future, 1st edn. (McGraw-Hill, New York, 1944)

14. R.S. McElvaine (ed.), Encyclopedia of the Great Depression (Macmillan Reference USA, New York, 2004)

15. United States. Congress, Gold Reserve Act of 1934 (1934) 
16. Federal Reserve History, Creation of the Bretton Woods System, https://www.federalreserveh istory.org/essays/bretton_woods_created

17. P. Salin, The International Monetary System and the Theory of Monetary Systems (Edward Elgar Publishing, 2016)

18. P.-O. Gourinchas, H. Rey, M. Sauzet, The International Monetary and Financial System, Working Paper No. 25782, National Bureau of Economic Research, 2019

19. B. Bernanke, Interview on CBS "60 Minutes", https://www.youtube.com/watch?v=hiCs_Y HIKSI

20. Deutsche Bundesbank, Monatsbericht November 2020, 72, 164 (2020)

21. M. McLeay, A. Radia, R. Thomas, Money Creation in the Modern Economy. Bank of England Quarterly Bulletin 2014, 14 (2014)

22. Basel Committee on Banking Supervision, Basel III Monitoring Report, Bank of International Settlements, 2020

23. S. Ugolini, The Evolution of Central Banking: Theory and History (Palgrave Macmillan, London, 2017)

24. F. Hutchinson, M. Mellor, W.K. Olsen, The Politics of Money: Towards Sustainability and Economic Democracy (Pluto, London ; Sterling, Va, 2002)

25. R. Dalio, Principles for Navigating Big Debt Crises (Greenleaf Book Group, Austin, 2018)

26. N. Irwin, Of Kiwis and Currencies: How a 2\% Inflation Target Became Global Economic Gospel, (The New York Times, 2014)

27. Kristalina Georgieva (Managing Director IMF), The Long Ascent: Overcoming the Crisis and Building a More Resilient Economy, https://www.imf.org/en/News/Articles/2020/10/06/sp1 00620-the-long-ascent-overcoming-the-crisis-and-building-a-more-resilient-economy

28. D. Helbing, Social Self-Organization: Agent-Based Simulations and Experiments to Study Emergent Social Behavior (Springer, Berlin, 2012)

29. D. Andrews, F. Petroulakis, Breaking the Shackles: Zombie Firms, Weak Banks and Depressed Restructuring in Europe., No. 2240, European Central Bank, 2019

30. Bloomberg, America's Zombie Companies Have Racked Up $\$ 1.4$ Trillion of Debt, Bloomberg.Com (2020)

31. C.M. Reinhart, K.S. Rogoff, This Time Is Different: Eight Centuries of Financial Folly (Princeton University Press, Princeton, 2009)

32. P. Bagus, In Defense of Deflation (Springer International Publishing, Cham, 2015)

33. F.P. Mongelli, D. Gerdesmeier, B. Roffia, The Fed, the Eurosystem, and the Bank of Japan: More Similarities or Differences?, https://voxeu.org/article/fed-eurosystem-and-bank-japansimilarities-and-differences

34. Board of Governors of the Federal Reserve System, The Federal Reserve System : Purposes and Functions, Board of Governors of the Federal Reserve System (U.S.), 2016

35. European Central Bank, ECB Monetary Policy, https://www.ecb.europa.eu/mopo/html/index. en.html

36. UN General Assembly, Transforming Our World: The 2030 Agenda for Sustainable Development, Division for Sustainable Development Goals: New York, NY, USA (2015)

37. K. Mainzer, Thinking in Complexity: The Computional Dynamics of Matter, Mind, and Mankind, 5th rev. and enl. ed (Springer, Berlin ; New York, 2007)

38. K. Raworth, Doughnut Economics: Seven Ways to Think Like a 21st-Century Economist (Random House Business, London, 2018)

39. K.-K. Kleineberg, D. Helbing, A "social bitcoin" could sustain a democratic digital world. Eur. Phys. J. Spec. Top. 225, 3231 (2016), reprinted in this volume

40. G. Dosi A. Roventini, More is different... and complex! The case for agent-based macroeconomics. J Evol Econ 29, 1 (2019)

41. D. Helbing, A. Kirman, Rethinking economics using complexity theory. Real-World Econ. Rev. 64, 23-51 (2013) http://www.paecon.net/PAEReview/issue64/HelbingKirman64.pdf

42. P. Ormerod, D. Helbing, Back to the drawing board for macroeconomics. Chap. 18 in D. Cole (ed) What's the Use of Economics? (London Publishing Partnership, 2012), pp 131-151 
43. C. Felber, This Is Not Economy: Aufruf Zur Revolution Der Wirtschaftswissenschaft (Paul Zsolnay Verlag, 2019)

44. P. Inman, Economics Students Call for Shakeup of the Way Their Subject Is Taught, The Guardian (2014)

45. F. Carapella, J. Flemming, Board of Governors of the Federal Reserve System, Central Bank Digital Currency: A Literature Review, FEDS Notes 2020, (2020)

46. B. Cœuré, J. Loh, Central Bank Digital Currencies, Bank for International Settlements (2018)

47. Governing Council of the European Central Bank, Report on a Digital Euro, European Central Bank (2020)

48. Group of Thirty, Digital Currencies and Stablecoins: Risks, Opportunities, and Challenges Ahead (2020)

49. IMF, Digital Money Across Borders: Macro-Financial Implications, International Monetary Fund (2020)

50. S. Zuboff, The age of surveillance capitalism: the fight for a human future at the new frontier of power, 1st edn. (PublicAffairs, New York, 2019)

51. K.S. Rogoff, The curse of cash (Princeton University Press, Princeton, 2016)

52. S. Nakamoto, Bitcoin: A Peer-to-Peer Electronic Cash System, https://bitcoin.org/bitcoin.pdf

53. IMF, World Economic Outlook Database: Report for Selected Countries and Subjects, https:// www.imf.org/en/Publications/WEO/weo-database/2020/October/weo-report

54. M. Friedrich, M. Weik, Der größte Crash aller Zeiten: Wirtschaft, Politik, Gesellschaft : wie Sie jetzt noch Ihr Geld schützen können (Eichborn, 2019)

55. N. Szabo, Shelling Out: The Origins of Money, https://nakamotoinstitute.org/shelling-out/

56. PlanB, Modeling Bitcoin Value with Scarcity, https://www.planBTC.com

57. P. Vigna, M.J. Casey, The Age of Cryptocurrency: How Bitcoin and Digital Money Are Challenging the Global Economic Order (St. Martin's Press, 2015)

58. F.A. Hayek, Denationalisation of Money-The Argument Refined (Ludwig von Mises Institute, 1990)

59. J.F. Nash, Ideal money. South. Econ. J. 69, 4 (2002)

60. B.H. Bratton, The stack: on software and sovereignty (MIT press, Boston, 2016)

61. W. Bickel, D. Christensen (eds) Behavioral Economics, in Encyclopedia of Psychopharmacology (Springer Berlin Heidelberg, Berlin, Heidelberg, 2015), pp 259-263

62. N. Beckstead, On the Overwhelming Importance of Shaping the Far Future, Dissertation, State University of New Jersey (2013)

63. M. Fare, P.O. Ahmed, Why Are Complementary Currency Systems Difficult to Grasp within Conventional Economics?, Revue Interventions Économiques. Papers in Political Economy (2018)

64. A.E. Kazdin, The Token Economy (Springer, US, Boston, MA, 1977)

65. R.H. Thaler, C.R. Sunstein, Nudge: improving decisions about health, wealth, and happiness (Yale University Press, New Haven, 2008)

66. R.H. Thaler, Behavioral economics: past, present, and future. Am. Econ. Rev. 106, 1577 (2016)

67. C. Vlek, L. Steg, Human behavior and environmental sustainability: problems, driving forces, and research topics. J. Soc. Issues 63, 1 (2007)

68. E. Ostrom, Governing the Commons: The Evolution of Institutions for Collective Action (Cambridge University Press, Cambridge; New York, 1990)

69. S. Voshmgir, M. Zargham, Foundations of Cryptoeconomic Systems, No. 1, Vienna University of Economics (2019)

70. B. Kewell, R. Adams, G. Parry, Blockchain for good? Strateg Chang 26, 429 (2017)

71. C. Dierksmeier, P. Seele, Cryptocurrencies and business ethics. J. Bus. Ethics 152, 1 (2018)

72. D.H. Meadows, D. Wright, Thinking in Systems: A Primer (London [u.a.]: Earthscan, 2009

73. M.C. Ballandies, M.M. Dapp, E. Pournaras, Decrypting distributed ledger design - taxonomy, classification and blockchain community evaluation. Cluster Comput. (2021). https://doi.org/ 10.1007/s10586-021-03256-w 
Open Access This chapter is licensed under the terms of the Creative Commons Attribution 4.0 International License (http://creativecommons.org/licenses/by/4.0/), which permits use, sharing, adaptation, distribution and reproduction in any medium or format, as long as you give appropriate credit to the original author(s) and the source, provide a link to the Creative Commons license and indicate if changes were made.

The images or other third party material in this chapter are included in the chapter's Creative Commons license, unless indicated otherwise in a credit line to the material. If material is not included in the chapter's Creative Commons license and your intended use is not permitted by statutory regulation or exceeds the permitted use, you will need to obtain permission directly from the copyright holder.

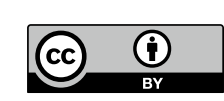

